\title{
INSTITUCIONALIZAÇÃO DA GESTÃO ESCOLAR NO BRASIL: EM FOCO AS PRIMEIRAS DÉCADAS DO SÉCULO XX (1911 - 1950)
}

\author{
Natalina Francisca Mezzari LOPES ${ }^{1}$ \\ Ricardo RIBEIRO ${ }^{2}$
}

RESUMO: Este trabalho visa investigar a institucionalização dos processos de gestão na legislação da educação brasileira. Para esse estudo delimitou-se as primeiras décadas do século XX (1911 - 1950). As leis no início do Brasil República foram derivadas da tradição ou forjadas pelos grandes legisladores. Por sua vez, a tradição representa o poder inserido na organização social que se conserva, de forma mais contundente, através das normas e regras. Com esse pressuposto, o estudo elegeu as Reformas Rivadávia e Carlos Maximiliano do início do século e as leis orgânicas do ensino para compreender como, neste contexto histórico, a legislação institucionalizou a função do diretor na educação básica. As reflexões apresentadas introduzem elementos históricos que demonstram ações e relações que permanecem em forma de hábitos nas gestões escolares. Estes elementos institucionalizados contribuem para o debate em torno das dificuldades políticas e pedagógicas sinalizadas por estudiosos e profissionais da área, relacionadas à promoção da gestão democrática na escola pública.

PALAVRAS-CHAVE: Gestão escolar. Diretor escolar. Legislação educacional.

\section{INTRODUÇÃO}

O presente trabalho versa sobre a institucionalização dos processos de gestão na legislação da educação brasileira no período de 1911 a $1950^{3}$. As leis nesse período foram derivadas da tradição ou forjadas pelos grandes legisladores. Por sua vez, a tradição representa o poder inserido na organização social que se conserva, de forma mais contundente, através das normas e regras. Compreendendo que a gestão escolar faz parte da normatização da educação, é possível dizer que nos processos administrativo e relacional do trabalho na escola ainda se mantêm práticas da tradição administrativa institucionalizada?

\footnotetext{
${ }^{1}$ Doutoranda em Gestão Escolar. UNESP - Universidade Estadual Paulista. Faculdade de Ciências e Letras - Pós-graduação em Gestão Escolar. Araraquara - SP - Brasil. 14800-901. UEM - Universidade Estadual de Maringá. Departamento de Fundamentos da Educação. Maringá - PR - Brasil. 87083-040 natalinamezzari@hotmail.com

${ }^{2}$ Doutorando em Gestão Escolar. UNESP - Universidade Estadual Paulista. Faculdade de Ciências e Letras - Pós-graduação em Gestão Escolar. Araraquara - SP - Brasil. 14800-901 despertarosol@gmail.com

${ }^{3}$ Este estudo recupera e amplia algumas discussões apresentadas na dissertação de mestrado: A Função do Diretor do Ensino Fundamental e Médio: uma visão histórica e atual, UNICAMP, 2003, sob orientação do Prof. Dr. James Patrick Maher.
} 
Para responder a tal inquietação o estudo visa explicitar como a função do diretor de escola pública foi institucionalizada na legislação educacional, tendo como recorte o início do século XX. As reflexões apresentadas introduzem elementos históricos que demonstram ações e relações que permanecem em forma de hábitos nas gestões escolares. Esses elementos legais contribuem para o debate em torno das dificuldades políticas e pedagógicas sinalizadas por estudiosos e profissionais da área, relacionadas à promoção da gestão democrática na escola pública.

Ao realizar o estudo da legislação da educação nesse período teve-se presente a preocupação de encontrar elementos legais que delimitassem a função de diretor de escola básica. No entanto, ao olhar para as Reformas Rivadávia (BRASIL, 1911) e Carlos Maximiliano (BRASIL, 1915), voltadas para os institutos superiores de educação, foi possível perceber a riqueza de detalhes sobre a organização da administração escolar. Estas normatizações se configuravam em indicativo para organizações de outros níveis de ensino. Nesse sentido, o estudo inicia com um olhar tangencial no qual recupera a organização administrativa dos institutos de educação e a função do diretor. Na sequência garimpa no Manifesto dos Pioneiros a presença requerida dos gestores escolares. Com as Leis Orgânicas do Ensino é apresentado como a função do diretor passou a ser requerida, mas controlada pelo sistema.

\section{UM OLHAR TANGENCIAL}

Ao estudar os processos de gestão escolar na perspectiva institucionalizada no início do Estado Republicano duas reformas voltadas para o institutos de educação superior apresentavam de forma destacada a organização da gestão: a Reforma Rivadávia (BRASIL, 1911) e Carlos Maximiliano (BRASIL, 1915).

Para a organização da gestão, a Reforma Rivadávia (art.5) cria o Conselho Superior de Ensino ${ }^{4}$ como órgão deliberativo, consultivo e fiscalizador dos institutos, que têm entre as suas competências a de "[...] tomar conhecimento e julgar em grau de recurso as resoluções das Congregações ou diretores.” (art.13/b). As Congregações eram compostas pelos professores ordinários e extraordinários efetivos e de um representante dos professores extraordinários honorários e livres docentes do instituto, eleito anualmente (art. 50) (BRASIL, 1911).

\footnotetext{
${ }^{4}$ Segundo Reforma Rivadávia (art.12) (BRASIL, 1911): “O Conselho Superior de Ensino compor-se-á dos diretores das faculdades de medicina do Rio de Janeiro e da Bahia, de direito de S. Paulo e de Pernambuco, da Escola Politécnica do Rio de Janeiro, do diretor do Colégio Pedro II e de um docente de cada um dos estabelecimentos citados."
} 
A autonomia do diretor circunscrevia-se na esfera administrativa e fiscalizadora. Ao diretor do instituto cabia: convocar as sessões da Congregação; impor as penas disciplinares aos discentes e aos docentes; velar pela exata observância das prescrições regulamentares concernentes à matrícula, cursos, exames, etc; fiscalizar a execução das penas impostas pelas outras autoridades; conceder licença a docentes e funcionários administrativos até 15 dias; fixar e autorizar despesas, fiscalizando as quantias pagas; assinar e carimbar certidões e atestados; entre outros (art.29). Já, à Congregação competia: eleger o diretor; aprovar os programas de ensino; propor ao Conselho Superior, por intermédio do diretor, as medidas aconselhadas para o aperfeiçoamento do ensino; eleger o representante da Congregação no Conselho Superior de Ensino; lançar taxas; rever as disposições regulamentares; entre outras (art. 60) (BRASIL, 1911).

O que se tem, é que com a Reforma Rivadávia (1911) a administração dos institutos é marcada pela separação entre o administrativo e pedagógico sob a égide da autonomia. O diretor representava a autoridade máxima na condução das questões administrativas do estabelecimento de ensino.

Em 1915, com a Reforma Carlos Maximiliano (BRASIL, 1915), o Conselho Superior de Ensino deixa de ser um órgão deliberativo para ser somente consultivo e fiscalizador do governo. Nos institutos mantêm-se o diretor e a Congregação. Entretanto, o diretor do instituto de ensino superior é escolhido e nomeado livremente pelo Presidente da República, dentre os professores do instituto ${ }^{5}$.

Com a Reforma de 1915, as competências do diretor, são ainda mais burocráticas e fiscalizatórias, sendo assim descritas:

[...] b) cumprir à risca o orçamento votado pela congregação e aprovado pelo Governo; [...] d) verificar se os professores esgotam os programas das respectivas cadeiras, declarar, em relatório, os nomes dos que o não fizerem, e aplicar a pena aos que nem duas terças partes ensinarem; [...] f) velar pelo fiel cumprimento dos deveres, por parte do pessoal administrativo; manter no instituto rigorosa disciplina; [...] i) apresentar ao Governo, anualmente, por intermédio do Conselho Superior do Ensino, relatório minucioso de tudo quanto ocorreu no instituto, a respeito da ordem, disciplina, observância das leis e do orçamento. (BRASIL, 1915, art.114).

Em ambas as reformas, Rivadávia (1911) e Carlos Maximiliano (1915), a autonomia do gestor seguia os pressupostos pautados na administração científica que na

5 “Os diretores são nomeados livremente pelo Presidente da República, dentre os professores catedráticos efetivos ou jubilados, de cada instituto de ensino, e são demissíveis ad nutum.” (BRASIL, 1911, art.113). 
primeira década do século XX se introduzia no Brasil, de uma forma bastante original, pela via pública de formação do trabalhador.

A função do diretor, nesse período, constitui-se como elemento importante na consolidação da estrutura hierárquica e burocrática da administração científica. A política educacional se institui no início do século por um lado sem comprometimento com os aspectos pedagógicos de formação humana, mas por outro com o caráter controlador presente na estrutura organizacional da sociedade.

\section{O MANIFESTO DOS PIONEIROS E AS LEIS ORGÂNICAS DO ENSINO}

O processo de industrialização, que vai se instalando a partir da década de 30, conjuga novos verbos para a política de desenvolvimento econômico e social. Acumular capital, expandir os lucros; capitalizar os interesses coletivos em benefício privado (nacional ou estrangeiro); ajustar-se ao desenvolvimento econômico mundial; criminalizar a questão social; racionalizar os gastos; entre outros. Ações estas que evidenciam as lutas entre os setores agrário-exportador e o urbano-industrial, entre o econômico e o político, entre o catolicismo e o publicismo e entre proprietários e trabalhadores.

Em 1939, em pleno período da $2^{\text {a }}$ Guerra Mundial e do desenvolvimento do capitalismo, as atenções direcionam-se para a defesa nacional justificada como proteção nacional contra as políticas totalitaristas e comunistas. Protegido pela Constituição de 1937 que debitava autoridade suprema ao presidente da República, Getúlio Vargas implanta por Decreto-lei o Plano Especial de Obras e Aparelhamento da Defesa Nacional. A educação mantém-se à margem da necessidade de formação para o trabalho, não atendendo as expectativas e as reivindicações dos educadores.

No campo educacional, a luta dos educadores pela construção de um Plano Nacional de Educação remonta o início da década de 1930. Sob os auspícios da revolução de 30, que levou ao poder Getúlio Vargas, foi apresentado o "Plano de Reconstrução Educacional" pelos educadores, através do Manifesto dos Pioneiros da Educação $^{6}$. Esse Plano pauta-se nos princípios de laicidade, da obrigatoriedade, da gratuidade, da universalização e da nacionalização do ensino fundamental. Com o Manifesto dos Pioneiros é devidamente recuperada e apresentada a preocupação com a

\footnotetext{
${ }^{6}$ Documento lançado, em 1932, no Rio de Janeiro e São Paulo, redigido por Fernando de Azevedo a pedido do grupo de renovadores da educação que, na IV Conferência Nacional da Educação, da Associação Brasileira de Educação (ABE), se contrapuseram ao grupo dos católicos liderados por Fernando de Magalhães.
} 
Administração Escolar ${ }^{7}$. Os educadores denunciam o estado de inorganicidade do aparelho escolar, debitam-no à "[...] falta de espírito filosófico e científico, na resolução dos problemas de administração escolar [...]" e à falta de autonomia aos educadores para dirigir e administrar a educação assegurando os meios materiais para poder realizá-la (AZEVEDO, 1958, p.59-81).

O Manifesto dos Pioneiros apresenta duas preocupações em relação à administração escolar. Uma delas refere-se à falta de formação do diretor e propõe que a mesma deve pautar-se no conhecimento filosófico e científico. E a outra preocupação volta-se para a função do diretor, afirmando a necessidade de autonomia para romper com a centralização das decisões educacionais. Reivindicam não qualquer autonomia, mas aquela que envolve decisões relacionadas aos aspectos do ensino, pautados na garantia de recursos financeiros pelo poder público.

A luta pela construção de um plano nacional de educação se impõe diante da falta de políticas de organização nacional do sistema de ensino. O caminho para efetivação de um plano educacional é tortuoso. A Constituição de 1934, marcada por um tom democrático com a presença da Assembleia Nacional Constituinte, é substituída três anos mais tarde sem a efetivação do plano nacional de educação, cuja elaboração tinha sido outorgada ao Conselho Nacional de Educação sem contar que a Constituição Federal de 1937 rompe com a vinculação de recursos para a educação. A gestão da educação fica a mercê de legislações decretadas segundo interesses políticos.

Com o avanço do processo de industrialização, na década de 1930 e seguinte, modelos tecnocráticos da administração empresarial são implementados no âmbito da política e da economia abrangendo o setor social, no qual se insere a educação. As exigências ditadas pelo progresso da manufatura de um trabalhador diferenciado daquele da agricultura, provoca uma expectativa maior sobre a formação educacional e profissional. A resposta para as exigências educacionais vem em forma de decretos.

Os Decretos-leis ${ }^{8}$, denominados de Leis Orgânicas do Ensino, tratam individualmente cada nível ou ramo de formação profissional e apresentam

${ }^{7}$ Segundo Ribeiro (1988, p.15, grifo do autor), a expressão Administração Escolar foi utilizada pela primeira vez, em 1883 nos Pareceres e Projetos de Ruy Barbosa, “[...] como título de certa área de problemas pedagógicos tratados em documentos nacionais. Só depois de 40 anos de uso indiscriminado da expressão Administração Escolar em relatórios e estatísticas oficiais é que o Manifesto dos Pioneiros, em 1933 [sic], vem mencioná-la com mais apropriado sentido."

${ }^{8}$ Nos últimos três anos do Estado Novo, foram postos em execução três Decretos-leis referentes ao ensino, que denominaram-se de Leis Orgânicas do Ensino (L.O.E.), a saber: a) D-lei n ${ }^{\circ}$ 4.073, de 30/01/42 (BRASIL, 1942b) - L. O. E. Industrial; b) D-lei no 4.244, de 09/04/42 (BRASIL, 1942c) - L. O. E. Secundário; c) D-lei $n^{\circ}$ 6.141, de 28/12/43 (BRASIL, 1943) - L. O. E. Comercial. E outros três 
preocupações de diferentes naturezas em relação ao ensino. Algumas dessas preocupações caracterizam-se pelo direcionamento geral - como fins, princípios, estrutura do curso e formação dos professores; outras preocupações apresentam-se mais regimentais - como a organização do programa curricular e da administração da escola. Essa legislação, apesar de expressar o interesse político de manter o controle do processo educacional, não representa um todo orgânico.

No período de 1937 a 1945 as Leis Orgânicas do Ensino cumprem, de certa forma, com a função norteadora da educação e garantem o controle da administração das escolas da educação básica (denominados de primário, ginasial e secundário). A função do diretor de escola fica assim configurada na Lei Orgânica do Ensino Secundário:

A administração de cada estabelecimento de ensino secundário estará
enfeixada na autoridade do diretor, que presidirá ao funcionamento
dos serviços escolares, ao trabalho dos professores, às atividades dos
alunos e às relações de comunidade escolar com a vida exterior,
velando porque regularmente se cumpra, no âmbito de sua ação, a
ordem educacional vigente no país. (BRASIL, 1942c, art.77).

A responsabilidade do diretor reside em presidir e não coordenar os serviços escolares, o trabalho do professor e as atividades dos alunos. Pode-se dizer que essa forma de entender a função do diretor engendra na estrutura organizacional da escola, o caráter autoritário e centralizador da estrutura burocrática e política tradicional.

Nessa legislação, é acrescido à função do diretor um elemento que extrapola o âmbito interno da escola que é a responsabilidade de manter uma relação com a comunidade. Relação essa necessária, especialmente para a manutenção do ensino. As especificidades apresentadas na atuação do diretor reafirmam a função estritamente administrativa, a exemplo das Reformas do Ensino Superior Rivadávia (1911) e Carlos Maximiliano (1915).

A Lei Orgânica do Ensino Agrícola (1946) reedita com o mesmo enfoque administrativo a função do diretor do ensino secundário, delimitando as ações relacionando-as às matrículas, regime de funcionamento, cursos de continuação e

Decretos-leis foram baixados durante o governo Provisório de José Linhares, a saber: a) D-lei no 8.529, de 02/01/46 (BRASIL, 1946a) - L. O. E. Primário; b) D-lei no 8.530, de 02/01/46 (BRASIL, 1946b) - L. O. E. Normal; c). D-lei no 9.613, de 20/08/46 (BRASIL, 1946e) - L. O. E. Agrícola. Nesse período também foi criado o Serviço Nacional de Aprendizagem Industrial através do D-lei $\mathrm{n}^{\circ} 4.048$, de 22/01/42 (BRASIL, 1942a) e o Serviço Nacional de Aprendizagem Comercial através do D-lei no 8.621 e 8.622, de 10/01/46 (BRASIL, 1946c; 1946d). Conferir Romanelli (1978). 
aperfeiçoamento, controle de frequência do professor, higiene escolar, eficiência administrativa e burocrática, campos de experimentação e atividades exteriores. As prescrições refletem a organização centralizada mantendo o eixo de atuação nos aspectos administrativos em prejuízo do pedagógico.

A Lei Orgânica do Ensino Primário (1946) apresenta um diferencial ao tratar do sistema de escolha dos diretores. Assim determina "[...] os diretores de escolas públicas primárias serão sempre escolhidos mediante concurso de provas entre professores diplomados, com exercício anterior de três anos, pelo menos, e, de preferência, entre os que hajam recebido curso de administração.” (BRASIL, 1946a, art.36)

A mudança de enfoque da forma de escolha do diretor de escola denota, em primeiro plano, a mudança na política nacional. Nesse período é promulgada a Constituição Federal de 1946, que apesar de consubstanciada pelo espírito liberal, ela apresenta características democráticas legitimadas pela Assembleia Nacional Constituinte, superando imperatividade da Constituição de 1937. Num segundo plano, é possível perceber a presença da luta dos educadores em relação à administração da educação, superando a nomeação do diretor puramente por interesses políticos, abrindo a possibilidades de concurso e valorizando a experiência do trabalhador da educação. E, por último, apresenta a necessidade de educadores com formação na área específica de administração para dirigir a escola.

É interessante observar que, em todas as Leis Orgânicas do Ensino, a função do diretor é tratada no âmbito das necessidades de um gerenciador das ações propostas pelo sistema para a escola. Nesse período não é evidenciada a necessidade da escola apresentar projetos para constituir a autonomia da ação administrativa. Por outro lado, sabe-se que a luta pela autonomia do diretor está diretamente articulada com as questões da manutenção e do financiamento da educação. As Constituições de 1937 e 1946 previam a gratuidade do ensino, porém com ressalvas ${ }^{9}$, o que supõe que apesar da determinação de percentuais mínimos dos impostos a serem aplicados na educação, não se tem a garantia de recursos públicos para o financiamento do ensino.

Considerando que a administração e o funcionamento da escola eram de responsabilidade do diretor, por um lado justifica a ênfase dada nas Leis Orgânicas à

\footnotetext{
${ }^{9}$ Na Constituição de 1937 (BRASIL, 1937, art.130): “O ensino primário é obrigatório e gratuito. A gratuidade, porém, não exclui o dever de solidariedade dos menos para com os mais necessitados; assim por ocasião da matrícula, será exigida aos que não alegarem, ou notoriamente não puderem alegar, escassez de recursos, uma contribuição módica e mensal para a caixa escolar." Na Constituição Federal de 1946, "II - O ensino primário é obrigatório e gratuito para todos; o ensino oficial ulterior ao primário sê-lo-á para quantos provarem falta ou insuficiência de recursos.” (BRASIL, 1946f, art. 168).
} 
função gerencial do trabalho do diretor; mas por outro lado, não justifica a falta de autonomia administrativa, uma vez que, supõe que o diretor deveria buscar recursos para a manutenção do ensino e da escola.

A ausência de artigos tratando da autonomia do diretor nas Leis Orgânicas de Ensino deve ser entendida no contexto do Estado intervencionista ${ }^{10}$ e burocrático vigente nesse período, que centralizava e controlava tudo, não escapando, certamente, o controle da escola. O que evidencia que "[...] o político tem precedência sobre o administrativo no cotidiano da escola pública.” (PARO, 2000, p.78)

Em 1954, sob a promessa de "descentralização dos serviços de inspeção do ensino secundário", são criadas, através da Portaria n 134 , do Ministério de Estado da Educação e Cultura, Inspetorias Seccionais do Ensino Secundário cuja função é “[...] orientar e fiscalizar a aplicação das leis e decretos que regulam o ensino secundário, competindo-lhes cumprir e fazer cumprir os regulamentos, portarias e instruções baixadas pelo Ministro da Educação e Cultura e pelo Diretor do Ensino Secundário.” (BRASIL, 1954, art.2). Entram no cenário as Inspetorias como órgãos fiscalizadores do sistema escolar e têm sua abrangência direta nas ações dos diretores de escola. Observase que o Inspetor Seccional é diretamente responsável pelo cumprimento das legislações, centralizando todas as decisões, até mesmo aquelas que seriam de responsabilidade do diretor e que poderiam representar uma forma de autonomia do trabalho do diretor. A confirmação vem, com o Artigo $4^{\circ}$ da Portaria, no qual define que “[...] o Inspetor Seccional promoverá reuniões dos Inspetores em exercício na área sob sua jurisdição, pelo menos uma vez por mês, de modo a garantir não só a unidade de ação, mas o aproveitamento, por todos, das experiências de cada um.” (BRASIL, 1954).

No artigo subsequente da Portaria $n^{\circ}$ 134/51 fica determinado que "[...] periodicamente, o Inspetor Seccional promoverá reuniões de Diretores, Professores, Secretários e Orientadores pedagógicos dos estabelecimentos existentes na área de sua jurisdição para discussão de assuntos referentes ao ensino ou problemas peculiares à área da seccional." (BRASIL, 1954, art.5). Tanto a uniformização de ações como as constantes reuniões podem significar um caráter controlador e de direcionamento de tudo o que acontece na escola. A autonomia do trabalho do dirigente da escola e de sua equipe pedagógica fica, assim, comprometida.

${ }^{10} \mathrm{O}$ Estado intervencionista se caracteriza pela acentuada intervenção estatal na economia pela via do planejamento econômico, pelo fortalecimento do poder dos técnicos e pelo reconhecimento dos direitos sociais. (HORTA, 1997, p.196-214). 


\section{ALGUMAS CONSIDERAÇÕES}

A institucionalização do trabalho do gestor escolar configurou-se na tecnoestrutura estatal que no início do século XX incorporava, de modo cada vez mais sistemático e permanente, o pensamento técnico-científico e as técnicas de planejamento. O elemento político essencial da tecnoestrutura é a hipertrofia do Executivo (IANNI, 1996). Fica evidenciada na organização da gestão educacional a verticalização administrativa que também abrange as funções do diretor escolar.

A relação de autoridade e subordinação institucionalizada constrói determinadas interações entre o grupo de trabalhadores da escola que, com o passar do tempo, se consolidam como cultura administrativa representando-se como poder inserido na organização escolar.

Considerando que as normatizações relacionadas à gestão escolar se afirmaram na tradição autoritária, centralizadora e tecnocrática desenvolveu-se a cultura de autoridade e de poder intrínseca aos ocupantes de níveis escalonares superiores. O poder sendo intrínseco, segundo Pagés et al. (1987), se constrói e se exerce através de regras, de dispositivos, de técnicas, da forma de funcionamento e se enraíza na prática cotidiana das organizações, transformando-se em hábitos. Esse poder se exerce pela forma ideológica de crenças e valores de forma articulada às questões econômicas, ideológicas, psicológicas e, principalmente, pela forma política como constrói a necessidade de respeito às regras.

O desafio está em aprender a participar na construção das regras, normas e leis como forma de desconstruir os hábitos arraigados e construir novas formas de relação que priorize a gestão democrática em todos os seus prismas e conceitos. Isso, necessariamente, implica num grau elevado de consciência, tanto do diretor quanto dos demais trabalhadores da escola e dos membros da comunidade.

\section{THE INTEGRATION OF INFORMATION AND COMMUNICATION TECHNOLOGIES IN SCHOOLS: THE POLITICAL PEDAGOGICAL PROJECT IN THIS CONTEXT}

ABSTRACT: This work aims to investigate the institutionalization of management processes in the legislation of the Brazilian education. For this study was considered the first decades of the twentieth century (1911-1950). The laws of Brazil in the early 
Republic were derived from tradition or forged by the great legislators. In turn, the tradition is inserted in the power of social organization that is preserved, in a more forceful manner, through the norms and rules. With this assumption, the study chose the Rivadávia and Carlos Maximiliano Reforms, both of the beginning of the century, and the Organic Laws of Teaching, granted by the government in this period, to understand how legislation institutionalized the role of the director in basic education in this context history. The reflections presented introduce historical elements that demonstrate actions and relationships that remain in the form of habits in the school managements. These institutionalized elements contribute to the debate about the political and pedagogical difficulties pointed out by scholars and professionals, related to the promotion of democratic management in the public school.

KEYWORDS: School management. School director. Educational legislation.

\section{REFERÊNCIAS}

AZEVEDO, F. A educação entre dois mundos. São Paulo: Melhoramentos, 1958.

BRASIL. Ministério da Educação e Cultura. Trata da descentralização dos serviços de inspeção do ensino secundário. Portaria n.134, de 25 de fevereiro de 1954. Diário

Oficial da União: República Federativa do Brasil, Rio de Janeiro, 25 fev. 1954.

Disponível em: <http://www.jusbrasil.com.br/diarios/2436788/pg-9-secao-1-diariooficial-da-uniao-dou-de-03-03-1954>. Acesso em: 03 fev. 2013.

Decreto n.8.529, de 2 de janeiro de 1946. Lei orgânica do ensino primário.

Diário Oficial da União: República Federativa do Brasil, Rio de Janeiro, 4 jan. 1946a. Disponível em: <http://www2.camara.leg.br/legin/fed/declei/1940-1949/decreto-lei8529-2-janeiro-1946-458442-publicacaooriginal-1-pe.html>. Acesso em: 10 mar. 2013.

Decreto-lei n.8.530, de 2 de janeiro de 1946. Lei orgânica do ensino normal.

Diário Oficial da União: República Federativa do Brasil, Rio de Janeiro, 4 jan. 1946b. Disponível em: <http://www.planalto.gov.br/ccivil_03/decreto-lei/1937-

1946/Del8530.htm>. Acesso em: 10 mar. 2013.

Decreto-lei n.8.621, de 10 de janeiro de 1946. Dispõe sôbre a criação do Serviço Nacional de Aprendizagem Comercial e dá outras providências. Diário Oficial da União: República Federativa do Brasil, Rio de Janeiro, 12 jan. 1946c. Disponível em: <http://www.planalto.gov.br/ccivil_03/decreto-lei/1937-1946/Del8621.htm>. Acesso em: 10 mar. 2013.

Decreto-lei n.8.622, de 10 de janeiro de 1946. Dispõe sôbre a aprendizagem dos comerciários, estabelece e deveres dos empregadores e dos trabalhadores menores relativamente a essa aprendizagem e dá outras providências. Diário Oficial da União: República Federativa do Brasil, Rio de Janeiro, 12 jan. 1946d. Disponível em: <http://www2.camara.leg.br/legin/fed/declei/1940-1949/decreto-lei-8622-10-janeiro1946-416558-publicacaooriginal-1-pe.html>. Acesso em: 03 fev. 2013. 
Decreto-lei n.9.613, de 20 de agosto de 1946. Lei orgânica do ensino agrícola.

Diário Oficial da União: República Federativa do Brasil, Rio de Janeiro, 22 ago.

1946e. Disponível em: <http://www.planalto.gov.br/ccivil_03/decreto-lei/1937-

1946/Del9613.htm>. Acesso em: 03 fev. 2013.

Constituição (1946). Constituição Federal de 1946. 1946f. Disponível em:

<http://www.planalto.gov.br/ccivil_03/constituicao/constituicao46.htm>. Acesso em: 10 mar. 2013.

Decreto-lei n.6.141, de 28 de dezembro de 1943. Lei orgânica do ensino

comercial. Diário Oficial da União: República Federativa do Brasil, Rio de Janeiro, 31 dez. 1943. Disponível em:

<http://legis.senado.gov.br/legislacao/ListaPublicacoes.action?id=6717>. Acesso em: 10 mar. 2013.

Decreto-lei n.4.048, de 22 de janeiro de 1942. Cria o Serviço Nacional de Aprendizagem dos Industriários (SENAI). Diário Oficial da União: República Federativa do Brasil, Rio de Janeiro, 24 jan. 1942a. Disponível em:

<http://www.planalto.gov.br/ccivil_03/decreto-lei/1937-1946/Del4048.htm>. Acesso em: 10 mar. 2013.

Decreto-lei n.4.073, de 30 de janeiro de 1942. Lei orgânica do ensino

industrial. Diário Oficial da União: República Federativa do Brasil, Rio de Janeiro, 9 fev. 1942b. Disponível em:

<http://www010.dataprev.gov.br/sislex/paginas/24/1942/4073.htm>. Acesso em: 10 mar. 2013.

Decreto-lei n.4.244, de 9 de abril de 1942. Lei orgânica do ensino secundário.

Diário Oficial da União: República Federativa do Brasil, Rio de Janeiro, 10 abr. 1942c. Disponível em: <http://www2.camara.leg.br/legin/fed/declei/1940-1949/decretolei-4244-9-abril-1942-414155-publicacaooriginal-1-pe.html>. Acesso em: 10 mar. 2013.

Constituição (1937). Constituição Federal de 1937. 1937. Disponível em: <http://www.planalto.gov.br/ccivil_03/constituicao/constituicao37.htm>. Acesso em: 10 mar. 2013.

Decreto n.11.530, de 18 de março de 1915. Reforma Carlos Maximiliano de 18 de março de 1915. Reorganiza o ensino secundário e superior na República. Diário Oficial da União: República Federativa do Brasil, Rio de Janeiro, 20 mar. 1915. Disponível em: <http://www2.camara.leg.br/legin/fed/decret/1910-1919/decreto-1153018-marco-1915-522019-republicacao-97760-pe.html>. Acesso em: 02 mar. 2013.

Decreto n.8.659, de 5 de abril de 1911. Reforma Rivadávia. Aprova a lei orgânica do ensino superior e fundamental na República. Diário Oficial da União: República Federativa do Brasil, Rio de Janeiro, 6 abr. 1911. Disponível em: <http://legis.senado.gov.br/legislacao/ListaPublicacoes.action?id=58698>. Acesso em: 02 mar. 2013. 
HORTA, J. S. B. Plano Nacional de Educação: da tecnocracia à participação democrática. In: CURY, C. R. J.; HORTA, J. S. B.; BRITO, V. L. A. Medo à liberdade e compromisso democrático: LDB e plano nacional da educação. São Paulo: Ed. do Brasil, 1997. p.137-206.

IANNI, O. Estado e planejamento econômico no Brasil. 6.ed. Rio de Janeiro: Civilização Brasileira, 1996.

PAGÉS, M. et al. O poder das organizações. Tradução de Maria Cecília P. Tavares e Sonia S. Favatti, São Paulo: Atlas, 1987.

PARO, V. H. Gestão democrática da escola pública. 3.ed. São Paulo: Ática, 2000.

RIBEIRO, J. Q. Ensaio de uma teoria da administração escolar. São Paulo: Saraiva, 1988.

ROMANELLI, O. O. História da educação do Brasil: 1930/1973. 9.ed. Petrópolis: Vozes, 1978. 